\title{
New stent for transapical mitral valve replacement in acute swine experiment
}

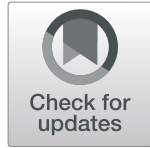

\author{
Yu Zou, Peng Teng and Liang Ma* (D)
}

\begin{abstract}
Background: Many patients with mitral regurgitation are denied open-heart surgery due to perceived high risk. Transcatheter mitral valve replacement is a therapeutic alternative for patients at high surgical risk. This study aimed to assess the feasibility of a new self-expanding valved stent for transcatheter mitral valve replacement via apex in an acute animal model.

Methods: Eight porcine experiments were performed in the acute study. A left thoracotomy was performed, and the new self-expanding transcatheter valved stent was deployed under fluoroscopic guidance in the native mitral annulus via apex. Hemodynamic data were recorded before and after implantation. Mitral annulus diameter and valve area were measured using echocardiography. Transvalvular and left ventricular outflow tract pressure gradients were measured using invasive methods.
\end{abstract}

Results: Seven animals underwent successful transapical mitral valve replacement; the implantation was unsuccessful in one animal. The mean procedure time, defined from placement to tightening of the purse-string suture, was $17.14 \pm 7.86 \mathrm{~min}$. Hemodynamic data before and after transapical mitral valve replacement showed no difference in statistical analysis. The mean diameter of the self-expanding device after implantation was $2.58 \pm 1.04$ $\mathrm{cm}$; the mean functional area was $2.70 \pm 0.26 \mathrm{~cm}^{2}$. Trace-to-mild central and paravalvular leaks were detected in 7 valves. The mean pressure gradient across the self-expanding device was $2.00 \pm 0.82 \mathrm{mmHg}$; the corresponding gradient across the LVOT was $3.28 \pm 1.11 \mathrm{mmHg}$. Postmortem evaluation confirmed precise device positioning in 7 animals with no signs of LVOT obstruction.

Conclusion: Transcatheter mitral replacement of the new valved stent was confirmed feasible in acute preclinical models. The new stent reveals optimal design parameters.

Keywords: Mitral regurgitation, Transcatheter mitral valve replacement, Self-expanding valved stent, Transapical

\section{Introduction}

Mitral regurgitation is one of the most common heart valve diseases worldwide $[1,2]$. Although valve repair is the treatment of choice [3, 4], replacement is still the gold standard, especially for complex cases or repair failure [5]. However, many patients are denied open-heart surgery due to perceived high risk $[6,7]$.

\footnotetext{
*Correspondence: m11402@zju.edu.cn

Department of Cardiovascular Surgery, the First Affiliated Hospital, College of Medicine, Zhejiang University, 79 Qing Chun Road, Hang Zhou 310003,

Zhejiang Province, China
}

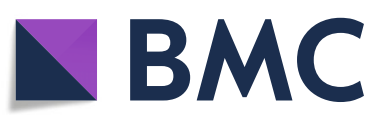

(C) The Author(s). 2021 Open Access This article is licensed under a Creative Commons Attribution 4.0 International License, which permits use, sharing, adaptation, distribution and reproduction in any medium or format, as long as you give appropriate credit to the original author(s) and the source, provide a link to the Creative Commons licence, and indicate if changes were made. The images or other third party material in this article are included in the article's Creative Commons licence, unless indicated otherwise in a credit line to the material. If material is not included in the article's Creative Commons licence and your intended use is not permitted by statutory regulation or exceeds the permitted use, you will need to obtain permission directly from the copyright holder. To view a copy of this licence, visit http://creativecommons.org/licenses/by/4.0/ The Creative Commons Public Domain Dedication waiver (http://creativecommons.org/publicdomain/zero/1.0/) applies to the data made available in this article, unless otherwise stated in a credit line to the data. ation (TAVI) is used increasingly with exciting results as a surgical alternative for high-risk patients $[8,9]$. Transcatheter mitral valve replacement (TMVR) is currently in the early clinical stage of development with reports of several devices and delivery systems [10, 11]. Although the results have been encouraging, the technique still faces many challenges due to the complex anatomy of the mitral apparatus, high ventricular pressure, and mitral annulus motion [12]. 
We developed a new self-expanding valved stent for transcatheter mitral valve replacement via apex. This study tests its feasibility in an acute animal model.

\section{Methods}

\section{The new valved stent}

The new stent (Fig. 1) is a self-expandable nitinol stent consisting of two components: (1) atrial fixation system with a D-shaped design; (2) circular ventricular part accommodating a trileaflet valve made of bovine pericardium. The D-shaped atrial frame that engages with the native mitral annulus helps stent fixation and reduces paravalvular leak. The flange sections of the two edges are wider than the flat aspect and the arc, specifically designed to fit the saddle-shaped mitral annulus. The asymmetric flange reduces the impact on the left ventricular outflow tract and prevents stent displacement. The trileaflet bovine valve is mounted on the circular ventricular body. A clip on the ventricular portion corresponds to the flat aspect of the D-shaped stent (Fig. 1c). The anterior leaflet is held between the clip and the ventricular body. A few struts are arranged radially on the ventricular component for anchoring (Fig. 1d arrow).

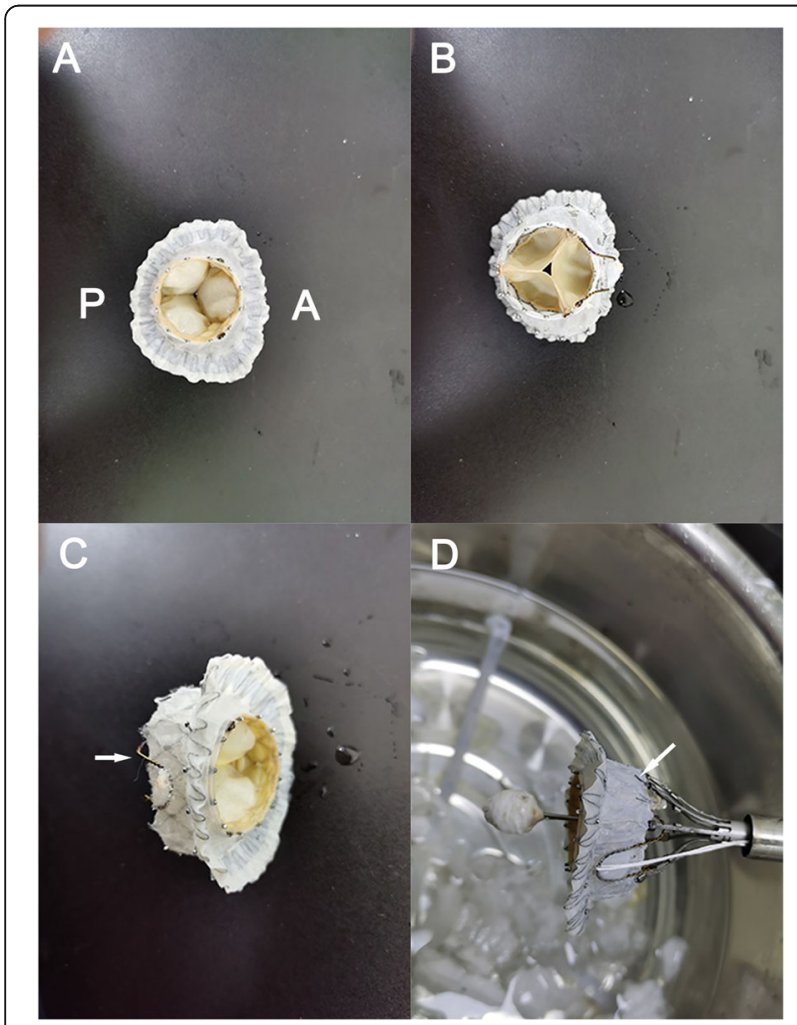

Fig. 1 The newly designed self-expanding nitinol valved stent. a Atrial view (A: facing anterior leaflet. P: facing posterior leaflet). $\mathbf{b}$ Ventricular view. c Side view. d The valved stent loaded into the delivery system. The clip ( $\mathbf{c}$ and $\mathbf{d}$ ) on the ventricular portion holds the anterior leaflet of the mitral valve
Three tethering strings attached to the lower part of the stent are fixed to the apex of the heart to prevent stent displacement. The stent frame is covered by a polyester fabric skirt to minimize paraprosthetic leaks, facilitating tissue ingrowth for long-term fixation and sealing.

\section{Delivery system}

The delivery system (Fig. 1d) is designed for transapical access only. The prosthesis is compressed and loaded into a 33Fr delivery capsule. It is advanced into the left ventricle via apex over the wire. Three knobs of the delivery system correspond to the three stages of deployment: atrial body expanding, ventricular expanding, and clip releasing. Rapid ventricular pacing is not required during the entire procedure.

\section{Animal preparation}

The study was approved by the local Ethics Research Board. Animals received care in compliance with the "Guide for the Care and Use of Laboratory Animals" prepared by the Institute of Laboratory Animal Resources and published by the National Institute of Health (NIH publication 85-23, revised 1985).

Eight porcine experiments (mean body weight of pigs was $46.45 \pm 3.72 \mathrm{~kg}$ ) were performed in this acute study. After administering general anesthesia with tracheal intubation and mechanical ventilation (intramuscular ketamine $22 \mathrm{mg} / \mathrm{kg}$ and atropine $0.8 \mathrm{mg} / \mathrm{kg}$, intravenous thiopental $15 \mathrm{mg} / \mathrm{kg}$ for induction, and isoflurane $2.5 \%$ for maintenance anesthesia), a coronary sinus electrode was inserted into the right internal regular vein using digital subtraction angiography (DSA) guidance to confirm the position of the mitral annulus. The right femoral artery was catheterized for monitoring blood pressure and blood sampling. The left femoral artery was implanted with a $5 \mathrm{~F}$ pigtail into the aortic root for aortic valve localization and angiograph. Arterial pressure, central venous pressure, oxygen saturation, and electrocardiography were monitored continuously.

\section{Transapical procedure}

A 5-cm left thoracotomy was performed. Double-purse string sutures were placed at the optimal access site of the left ventricular apex. The valved stent was $10 \%$ larger than the diameter of the native mitral annulus measured by CT and epicardial echocardiography. Left ventricular angiography was performed to determine the position of the mitral annulus. A stiff wire was introduced across the mitral valve into the pulmonary vein; the delivery system was advanced along the guide wire into the left atrium, using DSA guidance. The atrial brim was expanded first. It was necessary to gradually adjust the conveyor to the proper position so that the flat aspect of the D-shaped stent was aligned with the aorta. (There is 
a directional mark on the conveyor). The delivery system was pulled down until the atrial flange was seated firmly on the floor of the left atrium. The ventricular body was deployed without rapid ventricular pacing, and the clip was released to hold the anterior valve. After achieving stability, the stent was completely separated from the conveyor. Three tethering strings attached to the stent were pulled out of the apex with the conveyer withdrawn. The length of the tethering strings was adjusted under real-time monitoring using echocardiography. The apical access site was closed with purse-string sutures. The tethering strings were fixed at the epicardial surface by knotting the polyester felts. The procedure was performed under fluoroscopic guidance (Fig. 2).

Device function and hemodynamic impact were assessed using epicardial echocardiography (Fig. 3) and angiography (Fig. 2f) at baseline and $30 \mathrm{~min}$ after implantation. The transprosthetic and trans-LVOT pressure gradients were measured. Left ventricular angiography was performed.

Continuous hemodynamic measurements were recorded for another $6-8 \mathrm{~h}$. The animals were sacrificed for postmortem evaluation and device inspection (Fig. 4).

\section{Statistical analysis}

Data were analyzed using SPSS v19 software for Windows. Variables were reported as mean \pm standard deviation (SD), and Student's T-test was used for comparison.

\section{Results}

Seven of eight animals underwent successful transapical mitral valve replacement. In one animal, device positioning failed because of premature stent separation from the delivery system due to incorrect placement, which led the ventricular portion of the stent to migrate into the left atrium. The mean procedure time, defined from placement to tightening of the purse-string suture, was $17.14 \pm 7.86 \mathrm{~min}$. Hemodynamic data before and after transapical mitral valve replacement are shown in Table 1 . The mean diameter of the native mitral annulus was $2.46 \pm 1.00 \mathrm{~cm}$, and the mean mitral valve area was $4.58 \pm 0.29 \mathrm{~cm}^{2}$ on echocardiographic evaluation; the mean diameter of the self-expanding device after implantation was $2.58 \pm 1.04 \mathrm{~cm}$, and the mean functional area was $2.70 \pm 0.26 \mathrm{~cm}^{2}$. No statistical difference existed in mitral diameter before and after implantation. However, the functional mitral valve areas showed significant differences before and after the procedure ( $\mathrm{Sig}=0.00$, $p<0.05)$. Of the 7 successful implants, all valve leaflets had normal mobility and function. Trace or mild central and paravalvular regurgitation was detected in 7 valves (Table 2). The mean pressure gradient across the selfexpanding device was $2.00 \pm 0.82 \mathrm{mmHg}$; the corresponding gradient across the LVOT was $3.28 \pm 1.11$ mmHg (Table 1).

Postmortem evaluation confirmed precise device positioning in 7 animals, with no LVOT obstruction (Fig. $4 \mathrm{~d}$ ). For the failed case, the ventricular body of the stent facing the posterior annulus was deployed at the left atrium. The body facing the anterior annulus was at the

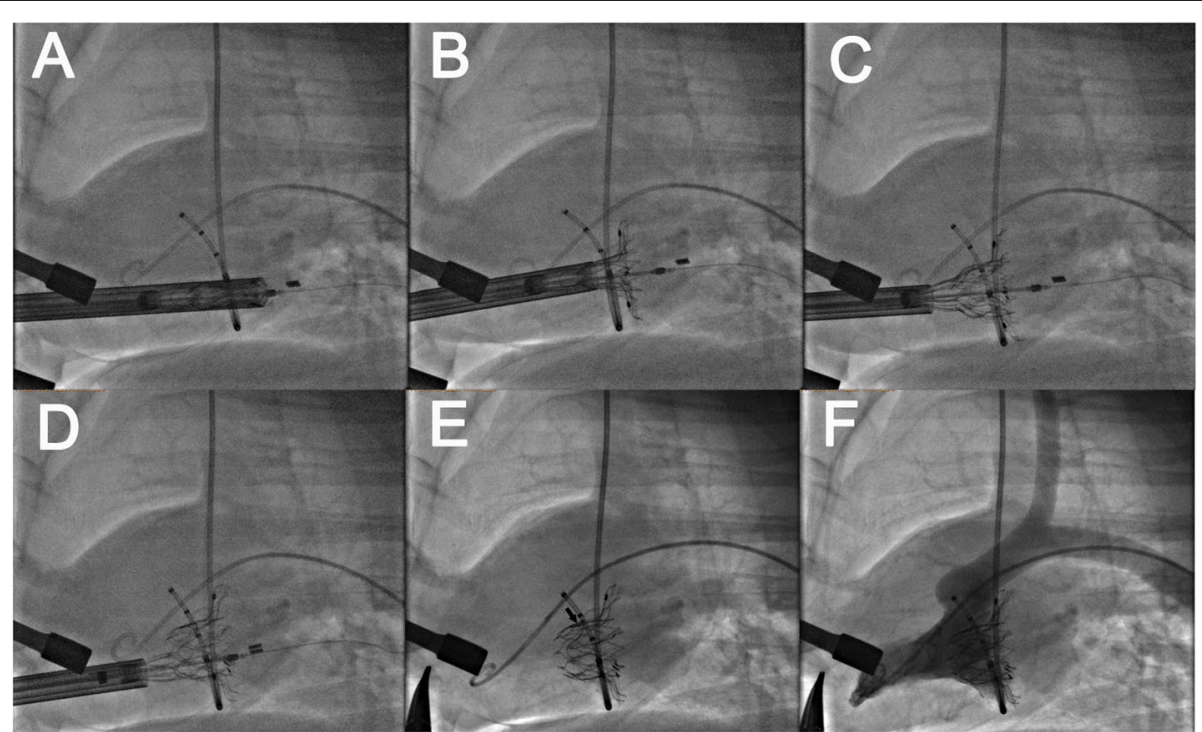

Fig. 2 a Delivery system advanced into the left atrium. b Atrial brim expansion. c Ventricular body deployed. $\mathbf{d}$ The clip released, and the stent separated from the conveyor completely. e The delivery system was withdrawn, and the stent was working. The arrow shows the clip. $\mathbf{f}$ Left ventricular angiogram shows no paravalvular regurgitation 


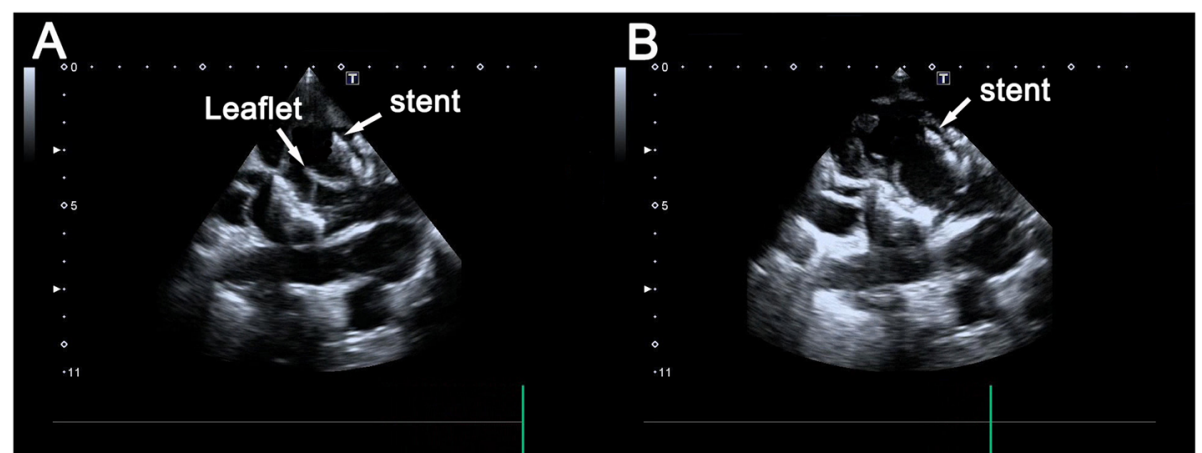

Fig. 3 Epicardial echocardiography reveals excellent device function with complete leaflet closing (a) and opening (b)

true position, securing the anterior leaflet between the clip and the stent. LVOT was not hindered.

\section{Discussion}

Unlike transcatheter aortic valve replacement (TAVR), the development of transcatheter mitral valve replacement faces unique challenges. The mitral valve is a complicated anatomic apparatus, including mitral leaflets, chordae, and papillary muscles. The non-circular saddleshaped annulus is pliable and changes during the cardiac cycle. Several vital structures, such as the circumflex coronary artery, atrioventricular node, and left ventricular outflow tract, are adjacent to the mitral valve [13]. Specifically, the anterior leaflet of the mitral valve is a part of the left ventricular output tract [14]. All of these features create a series of technical difficulties.

Although several challenges exist in TMVR, the TMVR system is rapidly expanding, with over 10 devices currently under development [15]. Several devices, such as Tendyne ${ }^{\mathrm{Tx}}$ (Abbott Vascular, Santa Clara, United States), Intrepid (Medtronic, MN, United States), Tiara ${ }^{\circ}$ (NeoVasc, Richmond, Canada), CardiaQ (Edwards
Lifesciences, Irvine, United States), are presently under clinical evaluation [16-20]. The transapical approach is the chief approach for TMVR. It provides easy access to the mitral valve and a simple stent-release procedure. The use of large-bore catheters (34- to 36-F) is allowed in the transapical approach. The transseptal approach has emerged as a hopeful alternative for TMVR. The technical difficulty and smaller sheath size limit its development [21].

The atrial portion of our device is " $\mathrm{D}$ " shaped to match the native mitral annulus. It is conducive to stent fixation and reduces paravalvular leakage. The flange section of the two edges is wider than the flat aspect and the arc, specifically designed to fit the saddle-shaped mitral annulus. The asymmetric flange minimizes left ventricular outflow tract obstruction and prevents stent displacement. A circular ventricular stent has three anchoring structures. First, radially struts are arranged on the ventricular component of the valved stent to penetrate the mitral leaflet and the valvular apparatus and prevent the device retrograde dislodgement into the atrium during systole. Second, a clip on the ventricular

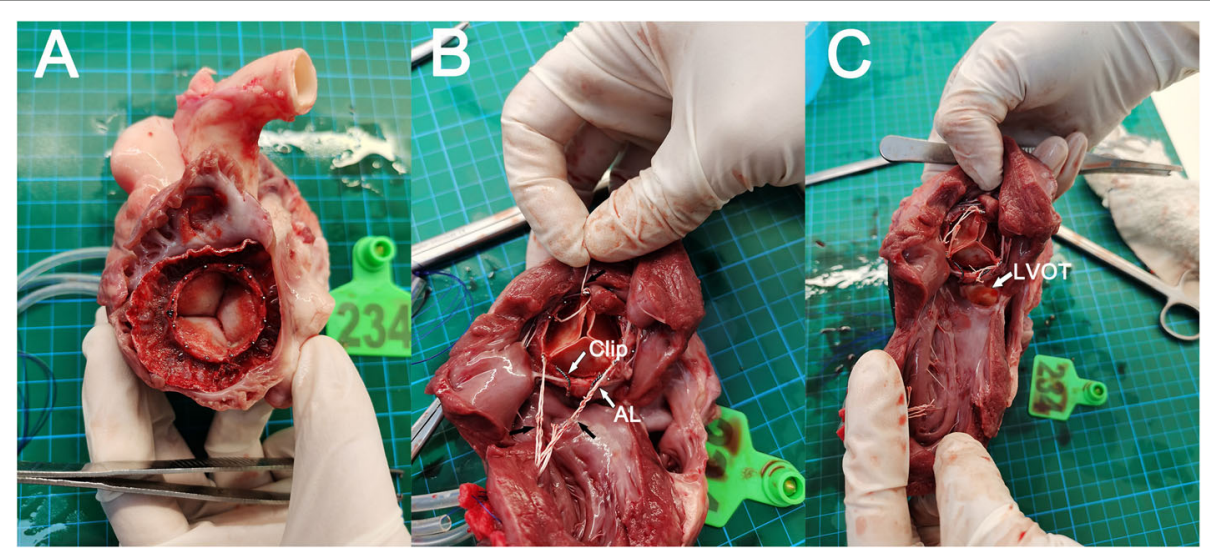

Fig. 4 Postmortem evaluation reveals accurate placement. a Left atrial side. b Left ventricular side (AL: anterior leaflet). Three tethering strings (black arrow) are attached to the lower part of the stent. c No signs of LVOT obstruction 
Table 1 Procedure and hemodynamic data

\begin{tabular}{|c|c|c|c|c|c|c|c|c|c|c|c|c|c|c|}
\hline \multirow[t]{2}{*}{ No. } & \multirow[t]{2}{*}{$\begin{array}{l}\text { Weight } \\
\text { (Kg) }\end{array}$} & \multicolumn{2}{|c|}{$\begin{array}{l}\text { HR } \\
\text { (bpm) }\end{array}$} & \multicolumn{2}{|l|}{$\begin{array}{l}\text { BP } \\
(\mathrm{mm} \mathrm{Hg})\end{array}$} & \multicolumn{2}{|c|}{$\begin{array}{l}\text { CVP } \\
(\mathrm{mm} \mathrm{Hg})\end{array}$} & \multicolumn{2}{|c|}{$\begin{array}{l}\text { Valve diameter } \\
(\mathrm{mm})\end{array}$} & \multicolumn{2}{|c|}{$\begin{array}{l}\text { Valve area }{ }^{a} \\
\left(\mathrm{~cm}^{2}\right)\end{array}$} & \multirow[t]{2}{*}{$\begin{array}{l}\text { Transapical time } \\
\text { (min) }\end{array}$} & \multirow[t]{2}{*}{$\begin{array}{l}\text { Across valve } \\
(\mathrm{mm} \mathrm{Hg})\end{array}$} & \multirow{2}{*}{$\begin{array}{l}\text { Across } \\
\text { LVOT } \\
(\mathrm{mm} \mathrm{Hg})\end{array}$} \\
\hline & & $\mathrm{Pr}$ & Po & $\mathrm{Pr}$ & Po & $\mathrm{Pr}$ & Po & Native & stent & Native & Stent & & & \\
\hline 1 & 43 & 125 & 130 & $123 / 92$ & $121 / 70$ & 10 & 9 & 23 & 25 & 4.30 & 2.53 & 33 & 3 & 5 \\
\hline 2 & 47 & 120 & 126 & $110 / 80$ & $100 / 67$ & 8 & 7 & 25 & 27 & 4.26 & 2.68 & 20 & 2 & 3 \\
\hline 3 & 53.6 & 112 & 120 & $103 / 62$ & 106/72 & 9 & 7 & 25.5 & 27 & 5.00 & 3.20 & 18 & 2 & 4 \\
\hline 4 & 50 & 123 & 112 & $98 / 53$ & $101 / 58$ & 11 & 8 & 25.1 & 27 & 4.23 & 2.83 & 11 & 1 & 4 \\
\hline 5 & 45.3 & 130 & 121 & 107/70 & $N$ & 8 & $N$ & 23.2 & 25 & 4.12 & $\mathrm{~N}$ & failed & n.a. & n.a. \\
\hline 6 & 43.7 & 110 & 113 & $117 / 73$ & $120 / 70$ & 10 & 8 & 23.5 & 25 & 4.31 & 2.38 & 10 & 1 & 2 \\
\hline 7 & 46 & 126 & 111 & $112 / 68$ & $118 / 72$ & 12 & 10 & 24 & 25 & 4.50 & 2.63 & 13 & 2 & 3 \\
\hline 8 & 43 & 112 & 130 & $120 / 81$ & $118 / 73$ & 7 & 9 & 23.2 & 25 & 4.18 & 2.67 & 15 & 3 & 2 \\
\hline Mean & 46.45 & 119 & 120 & $111 / 72$ & $112 / 69$ & 9.38 & 8.29 & 24.06 & 25.75 & 4.36 & 2.70 & 17.14 & 2.00 & 3.28 \\
\hline SD & 3.72 & 7.54 & 7.84 & $8.55 / 12.11$ & $9.29 / 5.18$ & 1.69 & 1.11 & 1.00 & 1.04 & 0.26 & 0.26 & 7.86 & 0.82 & 1.11 \\
\hline
\end{tabular}

Across LVOT Gradient across LVOT, Across valve Gradient across valve, BP Blood pressure, CVP Central venous pressure, HR Heart rate, n.a. Not available (due to failed implantation), post after implantation, pre before implantation, SD Standard deviation

${ }^{a}$ Differences between native and stent were statistically significant

portion corresponds to the position of the anterior leaflet of the mitral valve. It is released to hold the anterior leaflet of the mitral valve after the ventricular component opens completely. The design minimizes left ventricular outflow tract obstruction caused by the native anterior leaflet. It also prevents the movement of the device into the left atrium. During the operation, we did not deliberately capture the anterior leaflet. As long as the flat aspect of the D-shaped stent is aligned with the anterior annulus of the mitral valve, the clip can easily hold the anterior leaflet after the left ventricular body is fully opened. Third, three tethering strings are attached to the lower part of the stent and fixed to the apex of the heart to prevent stent displacement. The early experiments showed that the posterior side of the stent shifted to the left atrium during systole. This finding may be related to the insufficient anchoring force between the device and the posterior annulus. We did not include a clip on the posterior of the stent as Tiara to avoid the risk of penetrating the posterior wall of the left ventricle. Therefore, we added three strings attached to the stent

Table 2 Mitral regurgitation

\begin{tabular}{lll}
\hline No. & CL & PVL \\
\hline 1 & Mild & Mild \\
2 & None & Mild \\
3 & trace & mild \\
4 & Mild & Trace \\
5 & None & Moderate to Severe \\
6 & Mild & Mild \\
7 & Trace & mild \\
8 & Trace & Mild \\
\hline
\end{tabular}

CL Central leak, PVL Perivalvular leak symmetrically that could be pulled out with the delivery system and sutured to the apex. Current TMVR devices presenting anchoring systems with clips or tethering strings have proved to be reliable. Tiara ${ }^{\circ}$ has three clips, two anterior and one posterior. Medtronic has two clips, called support arms. In our device, the single-clip design makes it easier to hold the anterior leaflet. Tendyne ${ }^{\mathrm{m}}$ uses a ventricular fixation system connected to the LV apex through a polyethylene tether [10]; the complementary combination of the clip and tether string achieves good results. No displacement happened in the seven animals.

Our self-expanding stent valve achieved good hemodynamic performance in the acute porcine model with no stent displacement and left ventricular outflow tract obstruction. Although a significant difference exists in the effective functional area between the stent valve and the natural valve, it was comparable to the conventional bioprosthetic valve. Therefore, this study confirmed the feasibility of the new valved stent and the delivery system. We plan to conduct a long-term animal experiment to observe the reliability of valve stents.

A limitation of this study is the use of healthy animal models with normal cardiac anatomy and physiology. The healthy pig is significantly different from the patient presenting with functional mitral regurgitation. Another limitation is that the study is an acute experiment. It is necessary to carry out chronic experiments to verify the reliability of valve stents.

\section{Conclusions}

The new transapical valved stent was feasible and safe for mitral valve replacement and showed promising hemodynamic performance in an acute study. 


\section{Abbreviations}

LVOT: Left ventricular outflow tract: TAVl: Transcatheter aortic valve implantation; TMVR: Transcatheter mitral valve replacement;

TAVR: Transcatheter aortic valve replacement

\section{Acknowledgements}

Not applicable.

\section{Authors' contributions}

(I) Conception and design: LM; (II) Administrative support: LM, YZ; (III) Provision of study materials or patients: $Y Z_{;}$(IV) Collection and assembly of data: YZ, PT; (V) Data analysis and interpretation: All authors; (VI)

Manuscriptwriting: All authors; (VII) Final approval of manuscript: All authors.

\section{Funding}

This work was supported by the National Natural Science Funding of China (81670350) and Zhejiang Province Public Welfare Technology Application Research Project (LGF19H020012).

\section{Availability of data and materials}

All data generated or analyzed during this study are included in this published article.

\section{Declarations}

\section{Ethics approval and consent to participate}

Animal study was approved by the Experimental Animal Ethics Committee of Zhejiang Chinese Medical University. All animals received human care in compliance with the Guide for the Care and Use of Laboratory Animals.

\section{Consent for publication}

Not applicable.

\section{Competing interests}

The authors declare that there is no conflict of interest.

Received: 5 December 2020 Accepted: 6 April 2021

Published online: 21 April 2021

\section{References}

1. Benjamin EJ, Virani SS, Callaway CW, Chamberlain AM, Chang AR, Cheng S, et al. Heart disease and stroke statistics-2018 update: a report from the American Heart Association. Circulation. 2018;137(12):e67-e492. https://doi org/10.1161/CIR.0000000000000558

2. Coffey $S$, Cairns BJ, lung B. The modern epidemiology of heart valve disease. Heart. 2016;102(1):75-85. https://doi.org/10.1136/heartjnl-2014-3 07020.

3. Enriquez-Sarano M, Schaff HV, Orszulak TA, Tajik AJ, Bailey KR, Frye RL. Valve repair improves the outcome of surgery for mitral regurgitation. A multivariate analysis. Circulation. 1995;91(4):1022-8. https://doi.org/10.1161/ 01.CIR.91.4.1022

4. Suri RM, Schaff HV, Dearani JA, Sundt TM 3rd, Daly RC, Mullany CJ, et al. Survival advantage and improved durability of mitral repair for leaflet prolapse subsets in the current era. Ann Thorac Surg. 2006;82(3):819-26. https://doi.org/10.1016/j.athoracsur.2006.03.091.

5. Gillinov AM, Wierup PN, Blackstone EH, Bishay ES, Cosgrove DM, White J, et al. Is repair preferable to replacement for ischemic mitral regurgitation? J Thorac Cardiovasc Surg. 2001;122(6):1125-41. https://doi.org/10.1067/mtc.2 001.116557.

6. Enriquez-Sarano M, Akins CW, Vahanian A. Mitral regurgitation. Lancet. 2009; 373(9672):1382-94. https://doi.org/10.1016/S0140-6736(09)60692-9.

7. Mirabel M, lung B, Baron G, Messika-Zeitoun D, Detaint D, Vanoverschelde $J$, et al. What are the characteristics of patients with severe, symptomatic mitral regurgitation who are denied surgery? Eur Heart J. 2007:28(11):135865. https://doi.org/10.1093/eurheartj/ehm001.

8. Elmariah S, Palacios IF, McAndrew T, Hueter I, Inglessis I, Baker JN, et al. Outcomes of transcatheter and surgical aortic valve replacement in highrisk patients with aortic stenosis and left ventricular dysfunction: results from the placement of aortic Transcatheter valves (PARTNER) trial (cohort a). Circ Cardiovasc Interv. 2013:6(6):604-14 https://doi.org/10.1161/ CIRCINTERVENTIONS.113.000650.
9. Abdel-Wahab M, El-Mawardy M, Richardt G. Update on transcatheter aortic valve replacement. Trends Cardiovasc Med. 2015;25(2):154-61. https://doi. org/10.1016/j.tcm.2014.10.001.

10. De Backer O, Piazza N, Banai S, Lutter G, Maisano F, Herrmann HC, et al. Percutaneous transcatheter mitral valve replacement: an overview of devices in preclinical and early clinical evaluation. Circ Cardiovasc Interv. 2014;7(3):400-9. https://doi.org/10.1161/CIRCINTERVENTIONS.114.001607.

11. Regueiro A, Granada JF, Dagenais F, Rodes-Cabau J. Transcatheter mitral valve replacement: insights from early clinical experience and future challenges. J Am Coll Cardiol. 2017;69(17):2175-92. https://doi.org/10.1016/j. jacc.2017.02.045.

12. Loger K, Pokorny S, Schaller T, Haben I, Frank D, Lutter G. Novel stent design for transcatheter mitral valve implantation. Interact Cardiovasc Thorac Surg. 2018;26(2):190-5. https://doi.org/10.1093/icvts/ivx289.

13. Navia JL, Baeza C, Maluenda G, Kapadia S, Elgharably H, Sadowski J, et al. Transcatheter mitral valve replacement with the NaviGate stent in a preclinical model. Eurolntervention. 2017;13(12):e1401-e9. PubMed PMID: 28923785. Epub 2017/09/20. https://doi.org/10.4244/EIJ-D-17-00210.

14. Urena M, Himbert D, Vahanian A. Pushing the boundaries of transcatheter mitral valve replacement. J Am Coll Cardiol. 2019;73(20):2535-7. https://doi. org/10.1016/j.jacc.2019.03.481.

15. Fiorilli PN, Herrmann HC. Transcatheter mitral valve replacement: rationale and current status. Annu Rev Med. 2020;71(1):249-61. https://doi.org/10.114 6/annurev-med-051418-060028.

16. Muller DWM, Farivar RS, Jansz P, Bae R, Walters D, Clarke A, et al. Transcatheter mitral valve replacement for patients with symptomatic mitral regurgitation: a global feasibility trial. J Am Coll Cardiol. 2017;69(4):381-91. https://doi.org/10.1016/j.jacc.2016.10.068.

17. Sorajja P, Moat N, Badhwar V, Walters D, Paone G, Bethea B, et al. Initial feasibility study of a new transcatheter mitral prosthesis: the first 100 patients. J Am Coll Cardiol. 2019;73(11):1250-60. https://doi.org/10.1016/j.ja cc.2018.12.066.

18. Bapat V, Rajagopal V, Meduri C, Farivar RS, Walton A, Duffy SJ, et al. Early experience with new transcatheter mitral valve replacement. J Am Coll Cardiol. 2018;71(1):12-21. https://doi.org/10.1016/j.jacc.2017.10.061.

19. Cheung A. Early experience of TIARA transcatheter mitral valve replacement system. Ann Cardiothorac Surg. 2018;7(6):787-91. https://doi.org/10.21037/a Cs.2018.09.05

20. Sondergaard L, Ussia GP, Dumonteil N, Quadri A. The CardiAQ transcatheter mitral valve implantation system. Eurolntervention. 2015;11(Suppl W):W76-7.

21. Vahanian A, Urena M, Himbert D. Transcatheter mitral valve replacement: the end of the beginning? J Am Coll Cardiol. 2019;73(11):1261-3. https:// doi.org/10.1016/j.jacc.2019.01.026.

\section{Publisher's Note}

Springer Nature remains neutral with regard to jurisdictional claims in published maps and institutional affiliations.

Ready to submit your research? Choose BMC and benefit from

- fast, convenient online submission

- thorough peer review by experienced researchers in your field

- rapid publication on acceptance

- support for research data, including large and complex data types

- gold Open Access which fosters wider collaboration and increased citations

- maximum visibility for your research: over $100 \mathrm{M}$ website views per year

At BMC, research is always in progress.

Learn more biomedcentral.com/submissions 